\title{
Correction to: How does 'banter' influence trainee doctors' choice of career? A qualitative study
}

David Wainwright ${ }^{*}$, Michael Harris ${ }^{1,3}$ and Elaine Wainwright ${ }^{1,2}$

\author{
Correction to: BMC Med Educ \\ https://doi.org/10.1186/s12909-019-1531-0
}

Following publication of the original article [1], the authors reported an error in the first paragraph of the 'Results' section.

First paragraph of 'Results' section in the original article:

Twenty of 24 participants (83\%) were female; nationally, $57.4 \%$ of FY2 doctors were female in 2014/5.

Corrected first paragraph of 'Results' section:

Seventeen of 24 participants (71\%) were female; nationally, 57.4\% of FY2 doctors were female in 2014/5.

\section{Author details}

'Department for Health, University of Bath, Claverton Campus, Bath BA2 7AY, UK. ${ }^{2}$ Department of Psychology, Bath Spa University, Bath, UK. Institute of Primary Health Care Bern (BIHAM), University of Bern, Bern, Switzerland.

Received: 11 July 2019 Accepted: 15 July 2019

Published online: 20 August 2019

\section{Reference}

1. Wainwright, et al. How does 'banter' influence trainee doctors' choice of career? A qualitative study. BMC Med Educ. 2019;19:104. https://doi.org/1 0.1186/s12909-019-1531-0.

\footnotetext{
* Correspondence: d.wainwright@bath.ac.uk

'Department for Health, University of Bath, Claverton Campus, Bath BA2 7AY, UK

Full list of author information is available at the end of the article
} 